\title{
Correction to: Osteoporosis medication use among Australian women over two decades
}

\author{
Amanda L Stuart ${ }^{1}$ • Julie A Pasco ${ }^{1,2,3} \cdot$ Mohammadreza Mohebbi $^{4} \cdot$ Mark A Kotowicz $^{1,2,3} \cdot$ Kara L Holloway-Kew $^{1}$. \\ Sarah M Hosking ${ }^{1} \cdot$ Lana J Williams $^{1}$
}

Published online: 1 July 2020

(C) International Osteoporosis Foundation and National Osteoporosis Foundation 2020

\section{Correction to: Archives of Osteoporosis.}

https://doi.org/10.1007/s11657-019-0661-7

The original version of this article, published 06 May 2020, unfortunately contained a mistake. The presentation of Figs. 2 $(\mathrm{a}, \mathrm{b}$ and $\mathrm{c})$ were incorrect. The corrected figures are given below.

$\triangle$ Amanda L Stuart

amandh@barwonhealth.org.au

1 IMPACT, the Institute for Mental and Physical Health and Clinical Translation, School of Medicine, Deakin University, Geelong, Australia

2 Melbourne Medical School-Western Campus, The University of, Melbourne, St Albans, Australia

3 University Hospital Geelong, Geelong, Australia

4 Biostatistics Unit, Faculty of Health, Deakin University, Geelong, Australia 
a) Whole group

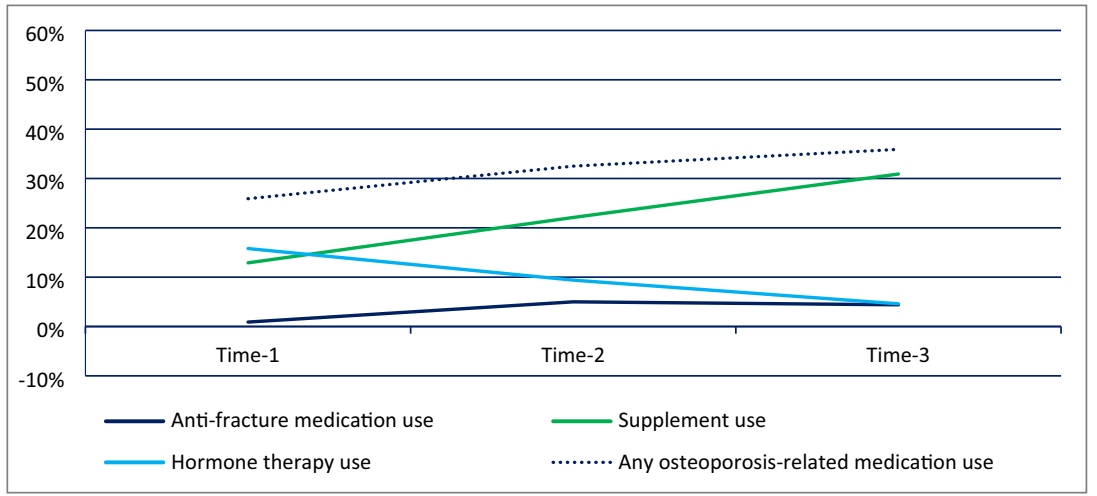

b) Women with osteoporosis by BMD criteria

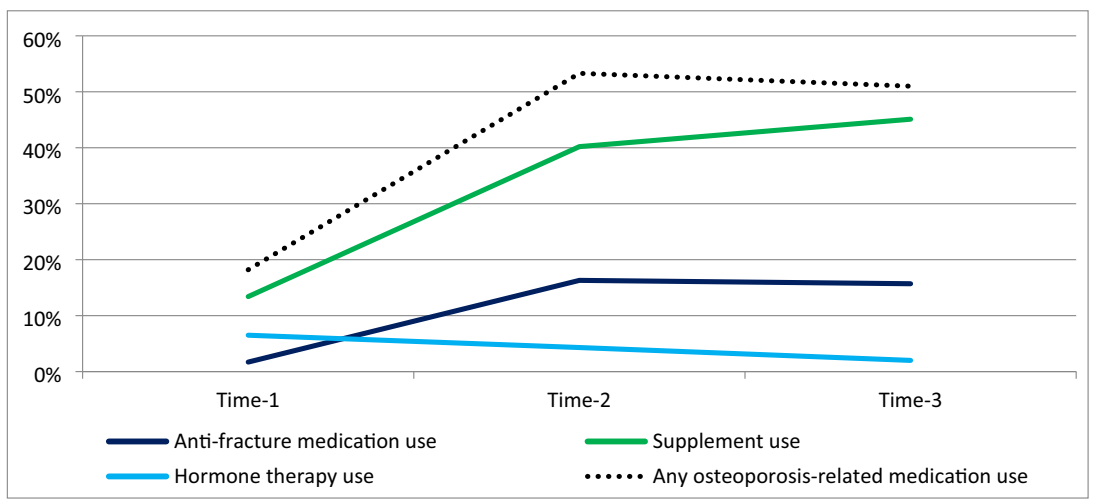

\section{C) Women at high risk of fracture according to the FRAX calculator}

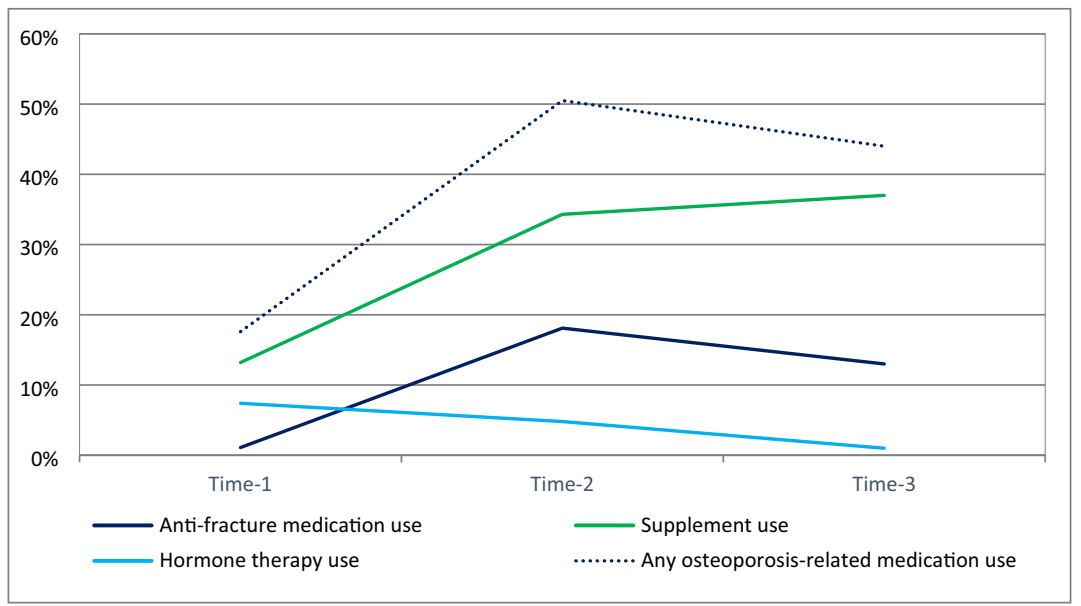

Publisher's note Springer Nature remains neutral with regard to jurisdictional claims in published maps and institutional affiliations. 